\title{
Study of $O$-Allylation Using Triazine-Based Reagents
}

\author{
Kohei Yamada, Naoko Hayakawa, Hikaru Fujita, Masanori Kitamura, and Munetaka Kunishima* \\ Faculty of Pharmaceutical Sciences, Institute of Medical, Pharmaceutical, and Health Sciences, Kanazawa \\ University; Kakuma-machi, Kanazawa 920-1192, Japan. \\ Received September 16, 2016; accepted October 18, 2016
}

Acid-catalyzed allylating reagent 2,4,6-tris(allyloxy)-1,3,5-triazine (TriAT-allyl) and its substituted derivatives have been developed. The reaction of acid-, and alkali-labile alcohols with these reagents in the presence of a catalytic amount of trifluoromethanesulfonic acid (TfOH) afforded the corresponding allyl ethers in good yields. Reactions using these reagents with an unsymmetrically-substituted regioisometric allyl group suggested that a single isometric allylic cation species would be involved.

Key words allylating reagent; triazine; allyl ether; acid catalyst

Previously, we developed acid-catalyzed benzylating reagents based on the chemistry of electron-deficient triazines, 2,4,6-tris(benzyloxy)-1,3,5-triazine $\left(\right.$ TriBOT) ${ }^{1-3)}$ and 2,4,6-tris (para-methoxybenzyloxy)-1,3,5-triazine (TriBOTPM) ${ }^{4)}$ which can be considered as a formal trimer of the smallest unit of benzyl imidates (Fig. 1). We have also reported the application of this concept to tert-butylating reagent, 2,4,6-tris(tert-butoxy)-1,3,5-triazine (TriAT- $t$ Bu). ${ }^{5)}$ These reagents have several common characteristic features, such as excellent reactivity, high stability, low cost, and high atom economy. Our next target is to expand this concept to allylating and substituted allylating reagents.

The allyl group has been widely employed for protection of hydroxy groups and carboxy groups, because the allyl group is orthogonally deprotected either by isomerization to a prop-1-enyl group and subsequent acid hydrolysis, or the formation of a $\pi$-allyl complex using transition metals. ${ }^{6,7)}$ Moreover, certain substituted allyl ethers and esters can be selectively cleaved in the presence of unsubstituted allyl ether and ester moieties using appropriate methods. ${ }^{8-10)}$ Both allyl and substituted allyl ethers have been used as monomer units in macromolecules. ${ }^{11-13)}$ Additionally, these ethers can be transformed into complex molecules possessing newly formed stereogenic centers by [2,3]-Wittig rearrangement or Claisen rearrangement via isomerization. ${ }^{14-17)}$ The introduction of allyl groups is generally performed using allyl 2,2,2-trichloroacetimidate (ATCAI) and a catalytic amount of acid, such as trifluoromethanesulfonic acid (TfOH) ${ }^{18-20)}$ or an allyl halides and base, such as sodium hydride $(\mathrm{NaH}){ }^{6,7)}$ These conventional methods have several drawbacks, such as poor stability, toxicity, and high cost ${ }^{21-25}$ ) which would be resolved by using alkylating reagents based on triazine chemistry. ${ }^{1-5)}$

Recently, an allylation using 2,4,6-tris(allyloxy)-1,3,5triazine was reported by another laboratory. ${ }^{26)}$ However, only one example was given in supporting information and detailed reaction conditions were not provided. Thus, we have established a practical, high-yielding procedure for this allylation.

In this report, we describe the development of an allylating reagent, 2,4,6-tris(allyloxy)-1,3,5-triazine (TriAT-allyl), and three substituted allyating reagents, namely 2,4,6-tris(methallyloxy)1,3,5-triazine (TriAT-methallyl), 2,4,6-tris(crotyloxy)-1,3,5triazine (TriAT-crotyl), and 2,4,6-tris(cinnamyloxy)-1,3,5triazine (TriAT-cinnamyl) ${ }^{27)}$ (Fig. 1).

TriAT-allyl, which is used as a cross-linking agent in polymer synthesis, ${ }^{28)}$ is commercially available. According to the optimized procedure for benzylation using TriBOT, the allylation of hexadecan-1-ol (1a) was conducted with TriAT-allyl and $\mathrm{TfOH}$ in 1,4-dioxane in the presence of powdered MS5A, which is a dehydrating agent to remove traces of moisture if any. However, the corresponding allyl ether $2 \mathbf{a}$ was afforded in a moderate yield (53\%, Table 1 , entry 1). As allyl cation species are less stable than benzyl cation species, ${ }^{29)}$ the consumption of TriAT-allyl took a long time (72h). Using 0.35 equiv. of TriAT-allyl and the same amount of $\mathrm{TfOH}$ was ef-

\section{Previous work}

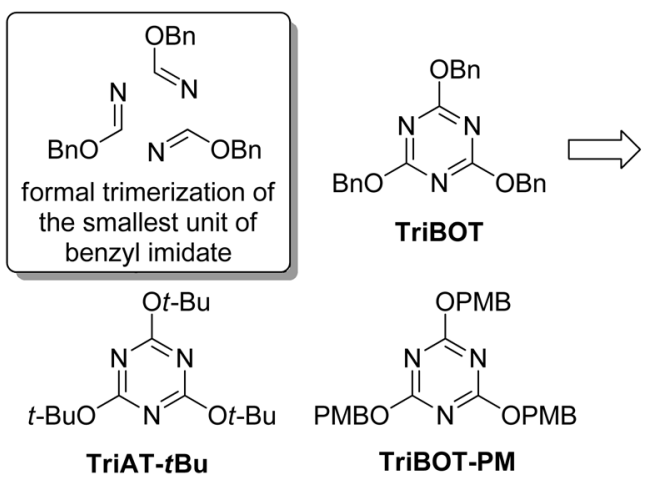

\section{This work}

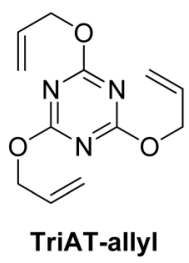<smiles>[R]C=C([R])COc1nc(OCC([R])=C[R])nc(OCC([R])=C[R])n1</smiles>

$\mathrm{R}^{1}=\mathrm{Me}, \mathrm{R}^{2}=\mathrm{H}$ : TriAT-methallyl

$\mathrm{R}^{1}=\mathrm{H}, \mathrm{R}^{2}=\mathrm{Ph}$ : TriAT-cinnamyl

$\mathrm{R}^{1}=\mathrm{H}, \mathrm{R}^{2}=$ Me: TriAT-crotyl

Fig. 1. Design Concept for Triazine-Based Allylating Reagents 
Table 1. Allylation of Alcohols and Carboxylic Acids

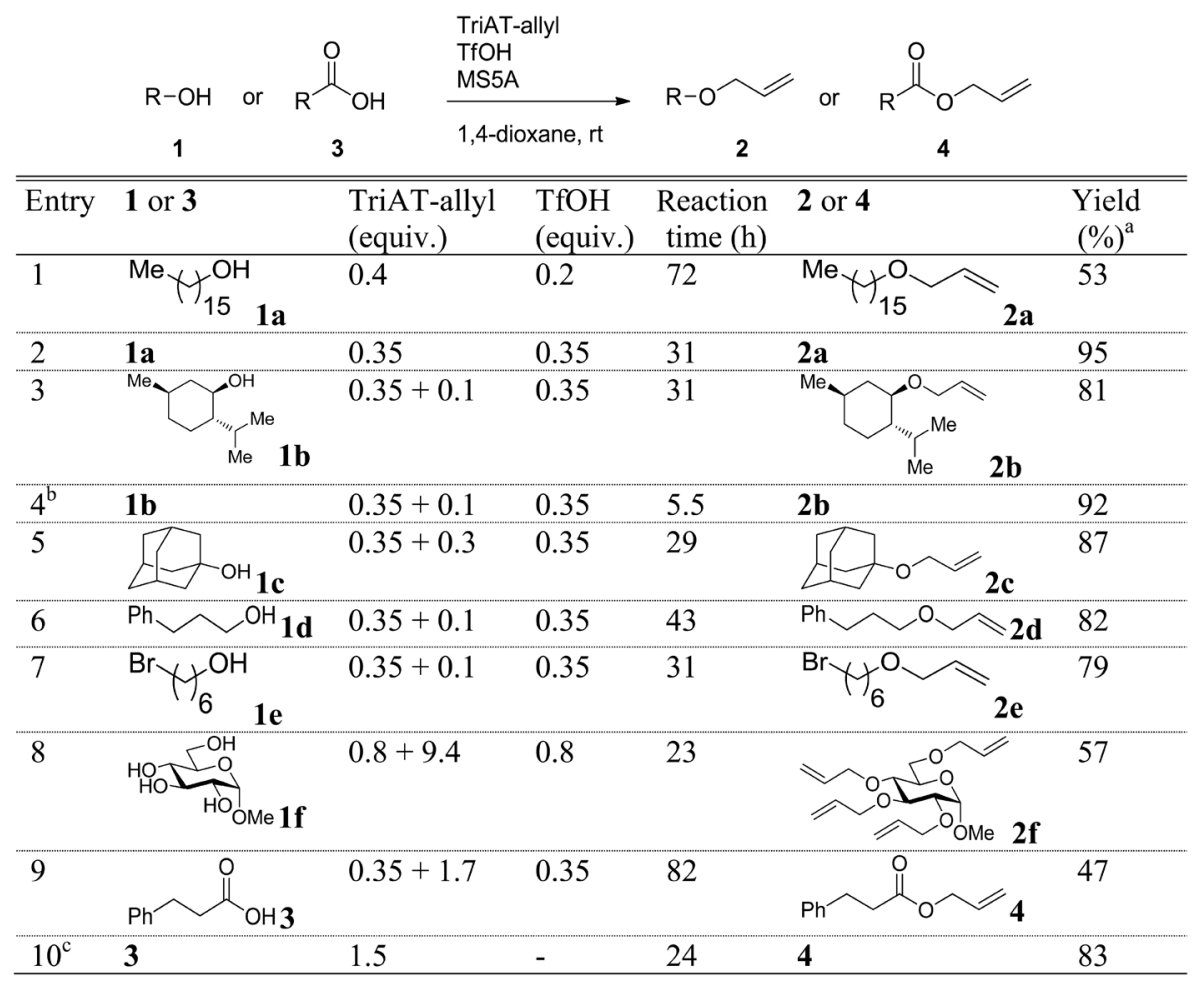

a) Isolated yield. $b$ ) Reaction was conducted at $50^{\circ} \mathrm{C}$. c) Reaction was conducted in 1,2-dichlorobenzene at $180^{\circ} \mathrm{C}$.

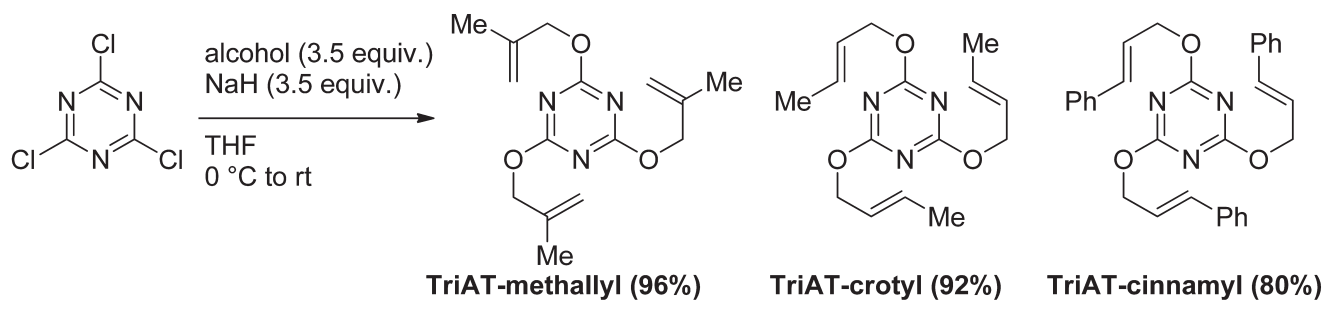

Chart 1. Synthesis of TriAT-Methallyl, TriAT-Crotyl, and TriAT-Cinnamyl

fective for the activation of TriAT-allyl, achieving a shorter reaction time $(31 \mathrm{~h})$ and an improved yield of $95 \%$ (entry 2$){ }^{1,30)}$ The reaction of secondary alcohol $\mathbf{1 b}$ afforded allyl ether $\mathbf{2 b}$ in $81 \%$ yield using an additional amount of TriAT-allyl (0.1 equiv.) (entry 3). Heating at $50^{\circ} \mathrm{C}$ shortened the reaction time to $5.5 \mathrm{~h}$ and improved the yield to $92 \%$ (entry 4). Tertiary alcohol 1c and aromatic ring containing alcohol 1d also provided the corresponding allyl ethers $\mathbf{2 c}$ and $\mathbf{d}$ in good yields (87 and $82 \%$, respectively, entries 5 and 6). Alcohol 1e, which possesses a base-labile bromoalkyl group, afforded product $\mathbf{2 e}$ in $79 \%$ yield (entry 7). Highly polar sugar tetraol $\mathbf{1 f}$ was successfully converted to its tetra-allyl sugar derivative $\mathbf{2 f}$ in $57 \%$ yield by adding a larger amount of TriAT-allyl (entry 8). The allylation of carboxylic acid $\mathbf{3}$ to give the corresponding allyl ester 4 resulted in a moderate yield (47\%, entry 9) because the basicity of the carboxylic acid, which could be related to the nucleophilicity of the acid, is less than that of alcohols. ${ }^{2,31)}$ Previously, we reported $O$-benzylation of carboxylic acids under thermal conditions without any additives, which would proceed via an $S_{N}$ 2-type mechanisms. ${ }^{2)}$ Thus, an attempt at the reaction under similar conditions of heating at $180^{\circ} \mathrm{C}$ without the acid catalyst improved the yield of 4 to $83 \%$ (entry 10 ).
Next, we studied the use of the substituted allylating reagents. According to the procedure for TriBOT-PM synthesis, ${ }^{4)}$ TriAT-methallyl, TriAT-crotyl, and TriAT-cinnamyl were prepared from the corresponding alcohols and cyanuric chloride in the presence of sodium hydride in 96,92 , and $80 \%$ yields, respectively (Chart 1).

The reaction of 1a using TriAT-methallyl and TfOH afforded corresponding methallyl ether $\mathbf{5 a}$ in $96 \%$ yield (Table 2, entry 1). For cinnamylation, the reactions could be conducted with a lower catalyst loading, because the corresponding reactive intermediate, a cinnamyl cation, was more stable than the benzyl and allyl cation species. ${ }^{29)}$ According to the procedure for para-methoxybenzylation using TriBOT-PM, ${ }^{4)}$ the reaction was conducted by dropwise addition of TriAT-cinnamyl solution ( 0.6 equiv.) in the presence of 0.05 equiv. of $\mathrm{TfOH}$ (entry 2). However, the products were obtained as a mixture of linear and branched isomers, 1-cinnamyl ether 6a-linear and 1-phenyl-prop-2-en-1-yl ether 6a-branch, in a 47:53 ratio. In the case of crotylation, using TriAT-crotyl ( 0.6 equiv.) and $\mathrm{TfOH}(0.2$ equiv.) also resulted in a mixture of 1-crotyl ether 7a-linear and its branched isomer, 1-methyl-prop-2-en-1-yl ether 7a-branch, in a 60:40 ratio (entry 3). We expected the 
Table 2. Methallylation, Crotylation and Cinnamylation of Alcohols

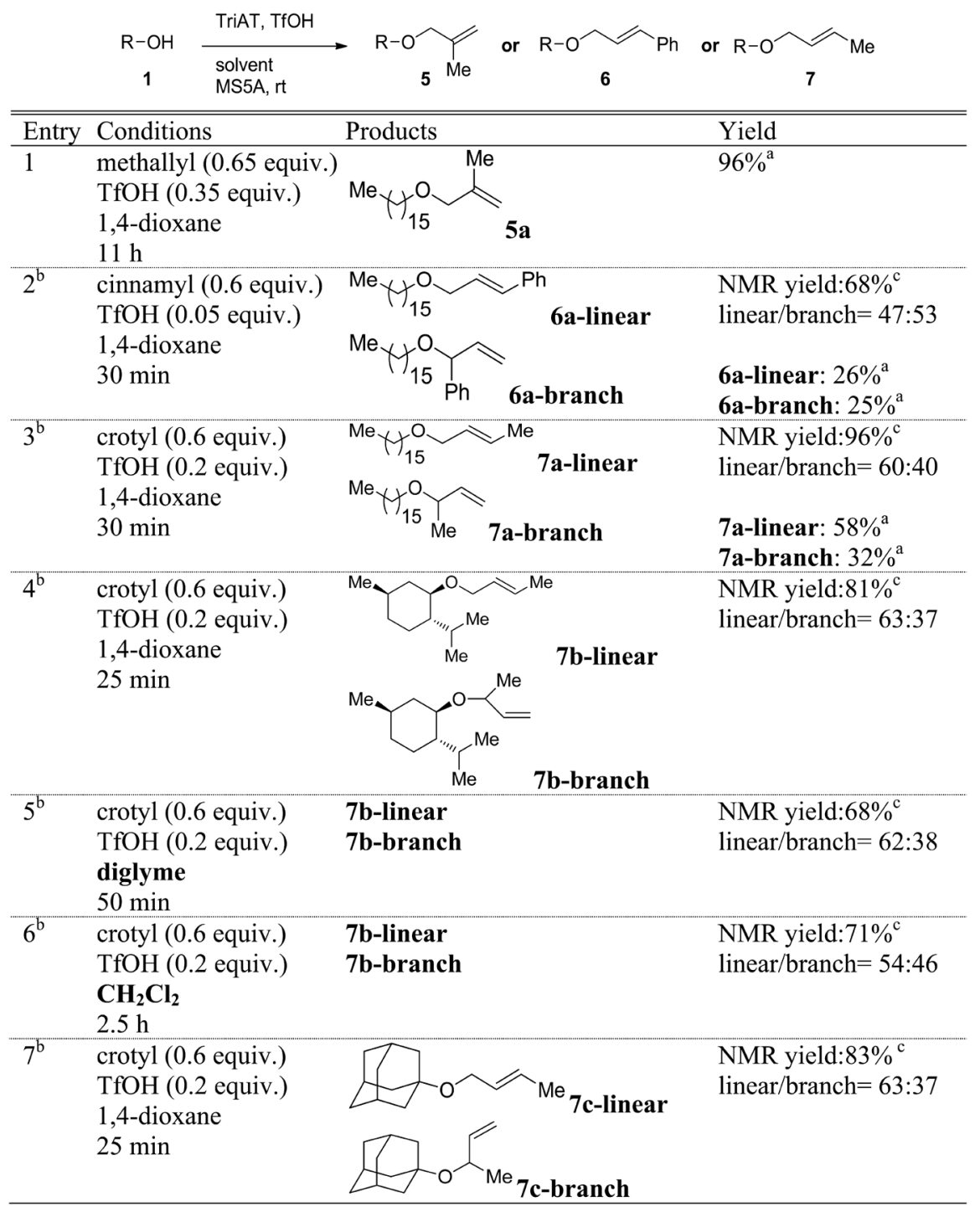

a) Isolated yield. $b$ ) A solution of TriAT was added dropwise over $8 \mathrm{~min} . c$ ) Yields and ratios of linear/branched isomers were calculated by ${ }^{1} \mathrm{H}-\mathrm{NMR}$ analysis using an internal standard.

linear/branched selectivity to improve when using sterically hindered secondary and tertiary alcohols $\mathbf{1 b}$ and $\mathbf{c}$ (entries 4, 7). Unfortunately, however, the regioselectivities of these reactions were similar to that of 1a (linear/branched $=63: 37$ ). The reaction of $\mathbf{1 b}$ using diglyme as an alternative ethereal solvent gave a similar ratio of products (linear/branched $=62: 38$, entry $5)$ while using dichloromethane as a solvent slightly decreased the ratio (linear/branched $=54: 46$, entry 6 ).

To obtain mechanistic insight into the crotylation, an alternative regioisomeric crotylating reagent, 8, was synthesized as a diastereomeric mixture (Chart $2 \mathrm{~A}$ ). The reaction of $1 \mathrm{a}$ with 8 proceeded to afford 7a-linear and 7a-branch in approximately the same ratio as that using TriAT-crotyl (linear/ branched $=59: 41$, Chart 2B). Interconversion between 7alinear and 7a-branch was not observed when treating with a catalytic amount of TfOH ( 0.2 equiv.) (Supplementary materials, Charts S1, S2). These results indicate that the same cationic intermediate (or the same ratio of regioisomeric intermediates such as allylic triflates) might be involved in allylations using TriAT-crotyl or $\mathbf{8}^{32-34)}$ (Chart 2C). The reactions of the other allylating reagents discussed herein might also proceed via the corresponding carbocation intermediates.

In conclusion, we successfully developed new acid-catalyzed allylating reagents, TriAT-allyl and its derivatives, based on triazine chemistry. As is the case in other triazine based alkylating reagents, these new reagents also showed remarkable reactivity in the allylation of alcohols and carboxylic acids, as well as excellent stability. Although cinnamylation and crotylation produced a mixture of linear and branched isomers, reactions using TriAT-crotyl or 8, comprised of a regioisomeric crotyl group, gave an important insight into the reaction intermediates.

Acknowledgments This work was partially supported by JSPS KAKENHI Grant Nos. 26293003, 26670001, 25460012 and by Adaptable and Seamless Technology Transfer Program through Target-driven R\&D (AS242Z03610M) from Japan Science and Technology Agency.

Conflict of Interest The authors declare no conflict of 
(A) Synthesis of 8

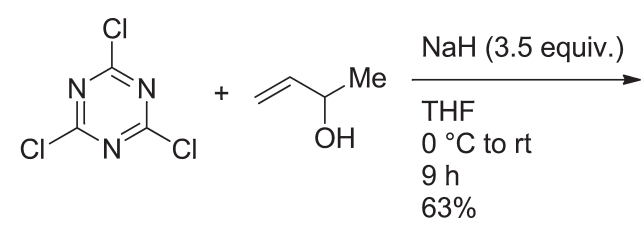<smiles>C=C[C@H](C)Oc1nc(O[C@H](C)C=C)nc(O[C@H](C)C=C)n1</smiles>

(B) Reaction of 1a using 8

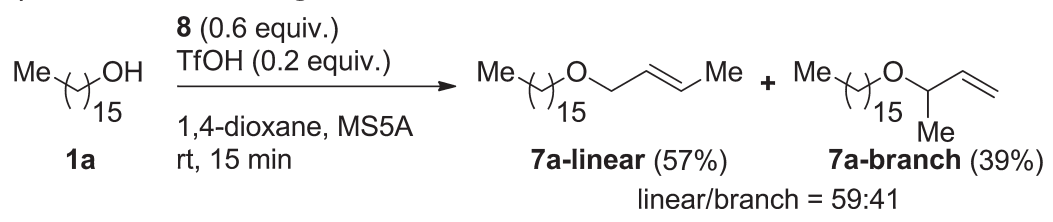

\section{(C) Plausible reaction mechanism}

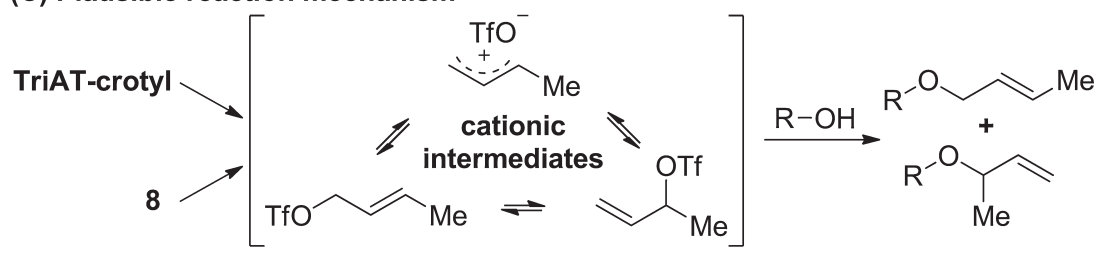

Chart 2. Experiments for Elucidation of the Reaction Mechanisms

interest.

Supplementary Materials The online version of this article contains supplementary materials (detailed experimental procedure, physical data, and NMR spectra of isolated products).

\section{References and Notes}

1) Yamada K., Fujita H., Kunishima M., Org. Lett., 14, 5026-5029 (2012).

2) Yamada K., Yoshida S., Fujita H., Kitamura M., Kunishima M., Eur. J. Org. Chem., 2015, 7997-8002 (2015).

3) Fujita H., Hayakawa N., Kunishima M., J. Org. Chem., 80, 1120011205 (2015).

4) Yamada K., Fujita H., Kitamura M., Kunishima M., Synthesis, 45, 2989-2997 (2013).

5) Yamada K., Hayakawa N., Fujita H., Kitamura M., Kunishima M., Eur. J. Org. Chem., 2016, 4093-4098 (2016).

6) Greene T. W., Wuts P. G. M., "Greene's Protective Groups in Organic Synthesis," 4th ed., Wiley-Interscience, New York, 2006.

7) Kocienski P. J., "Protecting Groups," 3rd ed., Thieme, Stuttgart, 2003.

8) Nashed M. A., Slife C. W., Kiso M., Anderson L., Carbohydr. Res., 82, 237-252 (1980)

9) Schmid C. R., Tetrahedron Lett., 33, 757-760 (1992).

10) Bartoli G., Cupone G., Dalpozzo R., De Nino A., Maiuolo L., Marcantoni E., Procopio A., Synlett, 2001, 1897-1900 (2001).

11) Takahashi E., WO2010/052916 (2010).

12) Takahashi E., WO 2011/086926 (2011).

13) Crivello J. V., U.S. Patent, 5886115 (1999).

14) Mikami K., Kishi N., Nakai T., Fujita Y., Tetrahedron, 42, 29112918 (1986).

15) Kunishima M., Hioki K., Kono K., Kato A., Tani S., J. Org. Chem., 62, 7542-7543 (1997).

16) Hioki K., Kono K., Tani S., Kunishima M., Tetrahedron Lett., 39, 5229-5232 (1998).

17) Reid J. P., McAdam C. A., Johnston A. J. S., Grayson M. N., Goodman J. M., Cook M. J., J. Org. Chem., 80, 1472-1498 (2015).

18) Wessel H.-P., Iversen T., Bundle D. R., J. Chem. Soc., Perkin Trans.
1, 1985, 2247-2250 (1985).

19) Burkholder T. P., Le T.-B., Giroux E. L., Flynn G. A., Bioorg. Med. Chem. Lett., 2, 579-582 (1992).

20) Kokotos G., Chiou A., Synthesis, 1997, 168-170 (1997).

21) Several methods for allylation using other allyl sources were reported. See refs. 22-25.

22) Beard C. D., Baum K., Grakauskas V., J. Org. Chem., 38, 36733677 (1973).

23) Vedejs E., Engler D. A., Mullins M. J., J. Org. Chem., 42, 31093113 (1977).

24) Tsabedze S. B., Kabotso D. E. K., Pohl N. L. B., Tetrahedron Lett., 54, 6983-6985 (2013).

25) Strayer T. A., Culy C. C., Bunner M. H., Frank A. R., Albiniak P. A., Tetrahedron Lett., 56, 6807-6809 (2015).

26) Cao P., Li Z.-J., Sun W.-W., Malhotra S., Ma Y.-L., Wu B., Parmar V. S., Nat. Prod. Bioprospect., 5, 37-45 (2015).

27) Prior to the report cited in ref. 26 being published, we had submitted a patent application referring to an allylation using TriATs, see: Kunishima M., Fujita H., Yamada K., PCT Int. Appl. 2013, WO 2013073681 A1 (2013).

28) For example.: Matsumoto A., Kubo T., Watanabe K., Aota H., Takayama Y., Kameyama A., Nakanishi T., Eur. Polym. J., 36, 673-677 (2000).

29) Kim J. D., Han G., Jeong L. S., Park H.-J., Zee O. P., Jung Y. H., Tetrahedron, 58, 4395-4402 (2002).

30) In comparison with this result ( $95 \%$ yield), the yield of allylation of a primary alcohol reported in ref. 26 is less than $60 \%$ even heated to $100^{\circ} \mathrm{C}$. Thus, we assume that the reaction conditions employed in the reference, which are not described in detail, are not different from our optimized conditions.

31) Kolthoff I. M., Anal. Chem., 46, 1992-2003 (1974).

32) It was reported that the reactions of both crotyl alcohol and its isomer, 1-methyl-prop-2-en-1-yl alcohol, using hydrogen bromide afforded corresponding butenyl bromide mixtures of regioisomers at approximately the same ratio, because the $S_{N} 1$ reaction involving crotyl cation species would be predominant over the $S_{N} 2$ reaction. See refs. 33 and 34.

33) Young W. G., Lane J. F., J. Am. Chem. Soc., 60, 847-853 (1938).

34) Roberts J. D., Young W. G., Winstein S., J. Am. Chem. Soc., 64, 2157-2164 (1942). 